In water, on water, and by water: mi micki ng nat ure's al dol ases wi th organocat al ysi s and wat er

\begin{tabular}{|l|l|}
\hline 著者 & Nase Nobuyuki, Bar bas Car I os F \\
\hline $\begin{array}{l}\mathrm{j} \text { our nal or } \\
\text { publ i cat } \mathrm{i} \text { on t i t l e }\end{array}$ & Organi c \& bi ondol ecul ar cheni stry \\
\hline vol une & 8 \\
\hline nunber & 18 \\
\hline page $r$ ange & $4043-4050$ \\
\hline year & $2010-07-09$ \\
\hline 出版者 & Royal Soci et y of Chemi st ry \\
\hline URL & ht t p: //hdl . handl e. net /10297/6161 \\
\hline
\end{tabular}




\title{
In Water, on Water, and by Water: Mimicking Nature's Aldolases with Organocatalysis and Water
}

\author{
Nobuyuki Mase ${ }^{*^{a}}$ and Carlos F. Barbas, III* ${ }^{* b}$ \\ Received (in $X X X, X X X$ ) Xth $X X X X X X X X X 200 X$, Accepted Xth $X X X X X X X X X 200 X$ \\ ${ }_{5}$ First published on the web Xth $X X X X X X X X X 200 X$ \\ DOI: 10.1039/b000000x
}

We review recent developments and applications of aldolase-type organocatalytic direct transformations in aqueous media without addition of organic solvent.

\section{Introduction}

10 Aldolases are essential, ubiquitous enzymes involved in glycolysis, gluconeogenesis and the Calvin cycle. They catalyze both carbon-carbon bond formation and cleavage in a stereoselective fashion in an aqueous in vivo milieu. For synthetic chemists, aldolases have become useful tools in 15 modern synthetic organic chemistry, in particular in carbohydrate synthesis; for instance, fructose 1,6-diphosphate aldolase (FDP aldolase) converts D-glyceraldehyde 3phosphate and dihydroxyacetone phosphate into D-fructose1,6-diphosphate reversibly in vitro. ${ }^{1}$ Native aldolases are 20 classified into two groups based on the mechanism of donor substrate activation. Class I aldolases activate substrates through an iminium ion formation step followed by enamine formation, whereas class II aldolases activate substrates by forming a zinc enolate. Development of a class I aldolase25 mimicking antibody catalyst have provided another useful tool in organic chemistry. ${ }^{2}$ Aldolase antibodies such as Ab $38 \mathrm{C} 2$ and its antipodal antibody siblings catalyze a wide variety of crossed and self-aldol reactions, including intramolecular aldol reactions in vitro. Aldolase antibodies also catalyzed 30 iminium-based Michael and decarboxylation reactions. ${ }^{3}$ The narrow substrate specificity of natural aldolases is vital for life, but not necessarily useful for organic synthesis. Interestingly, antibody aldolases catalyze reactions involving over 100 different substrate combinations with high rate 35 enhancements.

Near the end of the 20th century, small metal-free organic molecules attracted attention as organocatalysts. 4 Organocatalysts that mimic aldolases were widely studied due to mechanistic insight and impetus gained through study of 40 aldolase antibodies and the versatility, maneuverability, simplicity, and safety promised by organocatalysis. In general, organocatalytic reactions are carried out in a one-pot operation by stirring a carbonyl compound, an amine and an electrophile in conventional organic solvents, such as DMSO,

${ }_{45} \mathrm{DMF}$, or $\mathrm{CHCl}_{3}$, which are toxic, flammable and volatile. Removal of water is not required for the formation of enamine intermediates that proceed to react directly with an electrophile. This water-tolerance is a desirable characteristic of an organocatalyst. However, unlike native aldolases or 50 aldolase antibodies, in the presence of bulk water aldolasetype organocatalytic reactions generally result in very poor yield and stereoselectivity. ${ }^{5}$ It is instructive to note that enzyme aldolases form a hydrophobic 'reaction flask' at their active site that diminishes contacts between bulk water and 55 the reaction transition states; small organocatalysts cannot form this protected pocket and, therefore, it has been assumed and most typically observed that organocatalytic reactions with aqueous solvents result in poor yield and stereoselectivity. It is a common misconception to consider ${ }_{60}$ enzymatic reactions as actually taking place 'in water'. An enzyme-catalyzed reaction might more instructively be regarded as taking place in organic solvent wherein the enzyme itself is essentially a water-soluble reaction flask that presents a stereodefined array of organic side-chains that ${ }_{65}$ affect catalysis. As noted by the Sharpless group, the use of water as the only supporting medium for a reaction provides for ease of product isolation, high specific heat capacity, high specific inductive capacity, unique redox stability and nonexhaustible resource, even if the rate acceleration is 70 negligible. ${ }^{6}$ This review highlights developments in bondforming reactions catalyzed by aldolase-type organocatalysts in aqueous media without addition of organic solvents (Figure $1)^{7}$

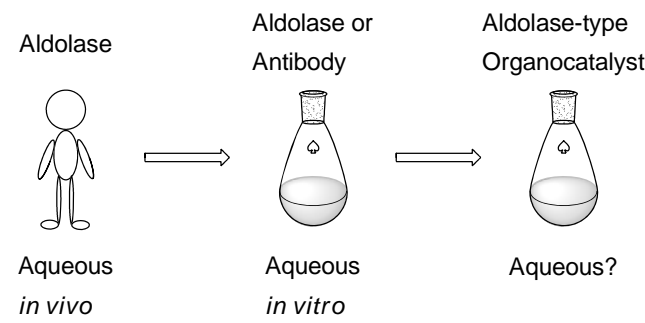

75 Figure 1. From aldolases in vivo to organocatalysis in water

\section{Direct asymmetric aldol reactions in aqueous media}

In the early 1970s, the Hajos group at Hoffmann-La Roche, Inc. ${ }^{8}$ and the Wiechert group at Schering A.-G. ${ }^{9}$ independently 80 reported the intramolecular direct aldol reaction of triketone 1 catalyzed by L-proline. Hajos' anhydrous condition in DMF afforded the aldol product (S)-2 in 100\% yield, subsequent acid-promoted dehydration provided (S)-Hajos-Wiechert ketone 3 in $99 \%$ yield with $95 \%$ ee. In contrast, Wiechert's 85 aqueous condition (in $\mathrm{MeCN} / 1 \mathrm{M} \mathrm{HClO}_{4}$ aq $=10 / 1, \mathrm{H}_{2} \mathrm{O} \approx 15$ equiv) directly produced the ketone 3 in $87 \%$ yield with $84 \%$ ee in one-pot operation (Scheme 1). A quarter-century later, the first organocatalytic intermolecular direct aldol reaction 
was reported by our group. Under our conditions, a small amount of water (less than 4 vol\%) did not affect the enantiomeric excess of aldol product, however $20 \mathrm{vol} \%$ water resulted in a substantial decrease in enantioselectivity. ${ }^{10}$

${ }_{5}$ Other early studies reported water-tolerant aldolase-type organocatalysts, but it was not possible to achieve high yield and stereoselectivity in the aqueous direct aldol reaction without addition of any organic solvent. ${ }^{5}$

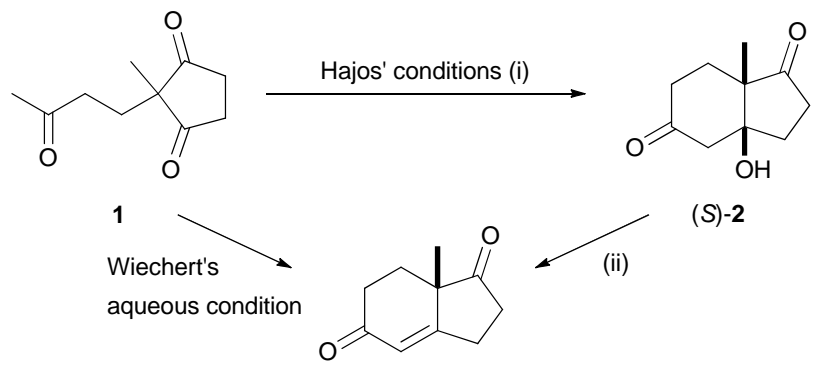

(S)-3

Hajos' conditions: (i) L-proline (3 mol\%), DMF, 20 h, under Ar, y. 100\% (ii) $0.01 \mathrm{M} p$ - $\mathrm{TsOH}$ in benzene, reflux, y. 99\%, 95\% ee

Wiechert's condition: L-proline (47 mol\%), MeCN/1 $\mathrm{M} \mathrm{HClO}_{4} \mathrm{aq}=10 / 1$, reflux, 22 h, y. $87 \%, 84 \%$ ee

10 Scheme 1. Organocatalytic synthesis of (S)-Hajos-Wiechert ketone 3

In 2006, the Hayashi group and our group independently reported two distinct strategies for aqueous organocatalytic direct cross-aldol reactions of various ketone and aldehyde donors with aldehyde acceptors. trans-L-Siloxyproline

15 (Figure 2, 4a) was a key catalyst for high diastereo- and enantioselectivities in the aldol reaction of cyclohexanone (19, 5 equiv) with $p$-nitrobenzaldehyde (20) in the presence of water (18 equiv); the reaction proceeds in a two-phase system (Table 1, entry 1). ${ }^{11}$ Without organic solvent or in an organic 20 solvent such as DMSO there is lower diastereo- and enantioselectivity. This high efficiency is probably due to the solubility of the catalyst $\mathbf{4 a}$ in organic solvent. Hydrophobic siloxyproline 4a is not very soluble in water but is soluble in the organic phase formed by the aldehyde and ketone 25 substrates. Although the role of water is not clear, water is essential for high stereoselectivity. Since these procedures use a small amount of water (3-18 equiv), these reactions are generally called "direct aldol reactions in the presence of water". ${ }^{12}$

${ }_{30}$ Our designed small diamine catalyst (5, $10 \mathrm{~mol} \%$ ) smoothly catalyzes the direct cross-aldol reaction of cyclohexanone (19, 2 equiv) with $p$-nitrobenzaldehyde (20) in bulk water (111 equiv), giving the aldol product $\mathbf{2 1}$ in quantitative yield with 94\% ee (Table 1, entry 2). ${ }^{13}$ Other ketones and aldehydes 35 were also efficient donors in this reaction. In addition, a stoichiometric amount of donor was enough to achieve the reaction thereby increasing the economy of the reaction (entry 3). Catalyst loading could also be decreased to $1 \sim 0.5 \mathrm{~mol} \%$ (entries 4 and 5), ${ }^{14}$ although no reaction was observed at 1 $40 \mathrm{~mol} \%$ catalyst loading using DMSO only as solvent. Furthermore, crude aldol products are easily isolated by removal of water using centrifugal separation; no extraction and washing are needed. The recovered catalyst as well as water can be used again (Scheme 2).<smiles>O=C1CCCC[C+]1Cc1ccc([N+](=O)[O-])cc1</smiles>

19

20<smiles>O=C1CCCC(C(O)[AlH2])C1O</smiles>

21
Table 1. The direct aldol reactions of cyclohexanone (19) with $p$ nitrobenzaldehyde (20) in aqueous media without addition of organic solvents

\begin{tabular}{ccccccc}
\hline Entry & $\begin{array}{c}\text { Catalyst } \\
(\mathrm{mol} \%)\end{array}$ & $\begin{array}{c}\text { Donor } \\
\text { (equiv) }\end{array}$ & $\begin{array}{c}\mathrm{H}_{2} \mathrm{O} \\
(\text { equiv) }\end{array}$ & $\begin{array}{c}\text { Yield } \\
(\%)\end{array}$ & $\begin{array}{c}\mathrm{De}^{a} \\
(\%)\end{array}$ & $\begin{array}{c}\mathrm{Ee}^{b} \\
(\%)\end{array}$ \\
1 & $\mathbf{4 a ( 1 0 )}$ & 5 & 18 & 86 & 90 & $>99$ \\
2 & $\mathbf{5}(10)$ & 2 & 111 & 99 & 78 & 94 \\
3 & $\mathbf{5}(10)$ & 1 & 111 & 98 & 70 & 92 \\
4 & $\mathbf{5}(1)$ & 2 & 111 & 91 & 62 & 91 \\
5 & $\mathbf{5}(0.5)$ & 2 & 111 & 81 & 62 & 89 \\
6 & $\mathbf{6}(2.5)$ & 1.2 & 111 & 97 & 86 & 93 \\
$7^{c}$ & $\mathbf{7}(0.5)$ & 4 & 55 & $\mathrm{NI}^{d}$ & 74 & 91 \\
8 & $\mathbf{8}(2)^{e}$ & 1 & 22 & 100 & 92 & $>99$ \\
9 & $\mathbf{9}(1)$ & 2 & 55 & 99 & $>98$ & 94 \\
10 & $\mathbf{1 0}(10)$ & 10 & 111 & 92 & 67 & 90
\end{tabular}

${ }^{a}$ Anti product was obtained as a major isomer. ${ }^{b}$ The ee is indicated for 50 the anti product. ${ }^{c}$ Brine was used as aqueous media. ${ }^{d}$ Not indicated in detail. ${ }^{e}$ Sulfated $\beta$-CD $(10 \mathrm{~mol} \%)$ was added.

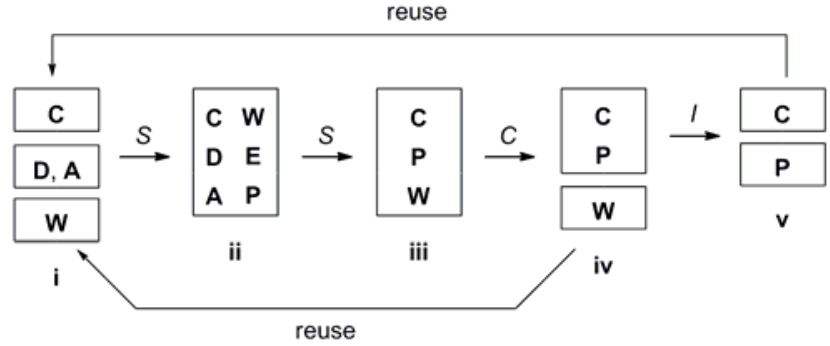

C: Catalyst, D: Donor, A: Acceptor, W: Water,

E: Enamine intermediate, $\mathbf{P}$ : Product

$S$ : Stirrer, $C$ : Centrifugation, $I$ : Isolation

Scheme 2. Easy phase separation and reuse of water and catalyst

Interesting temperature-dependent changes were observed in 55 this system (Figure 3). When this direct aldol reaction was carried out in DMSO at $10 \mathrm{~mol} \%$ catalyst loading, enantioselectivity sharply decreased to $52 \%$ ee as the temperature was raised to $50{ }^{\circ} \mathrm{C}$. This observation, decreasing ee with increasing temperature, is quite general in asymmetric 60 synthesis in organic solvents. On the other hand, with water as solvent, the enantioselectivity was only slightly decreased at elevated temperature and $10 \mathrm{~mol} \%$ catalyst loading $(94=>$ $90 \%$ ee). At $0.5 \mathrm{~mol} \%$, reactivity was improved and enantioselectivity was maintained (y. $52=>86 \%, 89=>72 \%$ $\left.{ }_{65} \mathrm{ee}\right) .{ }^{14}$ These results suggested that hydrophobic interaction plays an important role for reactivity as well as high enantioselectivity, since increased temperature (= entropy) leads to an increased hydrophobic effect. 
<smiles>[R6]C1CNC(C(=O)O)C1</smiles>

4a: $R=$ TBS

$4 \mathrm{~b}: \mathrm{R}=\mathrm{TBDP}$<smiles>CCCCCCCCCC[NH+](CCCCCCCCCC)CC1CCCN1</smiles>

5<smiles>CC(NC(=S)C1CCCN1)c1ccccc1</smiles>

6<smiles>O=C(NC(c1ccccc1)C(O)(c1ccccc1)c1ccccc1)C1CCCN1</smiles>

7

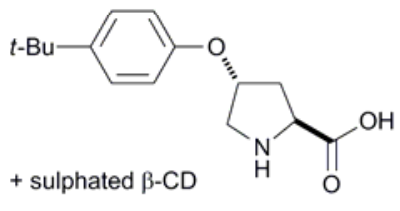

8<smiles>CCCO[C@H]1CN[C@@H](C(=O)N[C@@H]([C@@H](O)C(=O)OCC)[C@@H](OCC)C(=O)OC)C1</smiles>

9<smiles>O=S(=O)(NCC1CCCN1)OC(F)(F)C(F)(F)F</smiles>

10<smiles>CCOC(C)C(N)C(=O)NC(c1ccccc1)C(O)(c1ccccc1)c1ccccc1</smiles>

11<smiles>COC(c1ccccc1)(c1ccccc1)C1CCCN1</smiles>

12: $(S)$ isomer ent-12: $(R)$ isomer

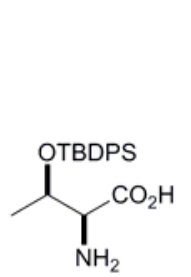

13

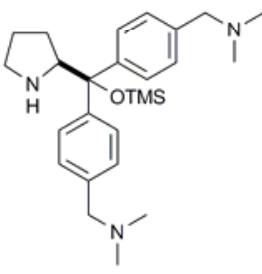

14

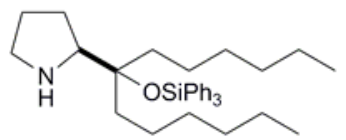

15<smiles>Cc1ccc(C2NC(Cc3ccccc3)C(=O)N2CC(=O)[O-])o1</smiles>

16

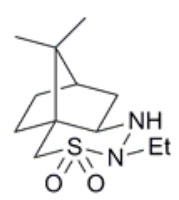

17<smiles>O=C[C@H](C(=O)[O-])c1cc(C(F)(F)F)cc(C(F)(F)F)c1</smiles>

18

Figure 2. Water-compatible aldolase-type organocatalysts

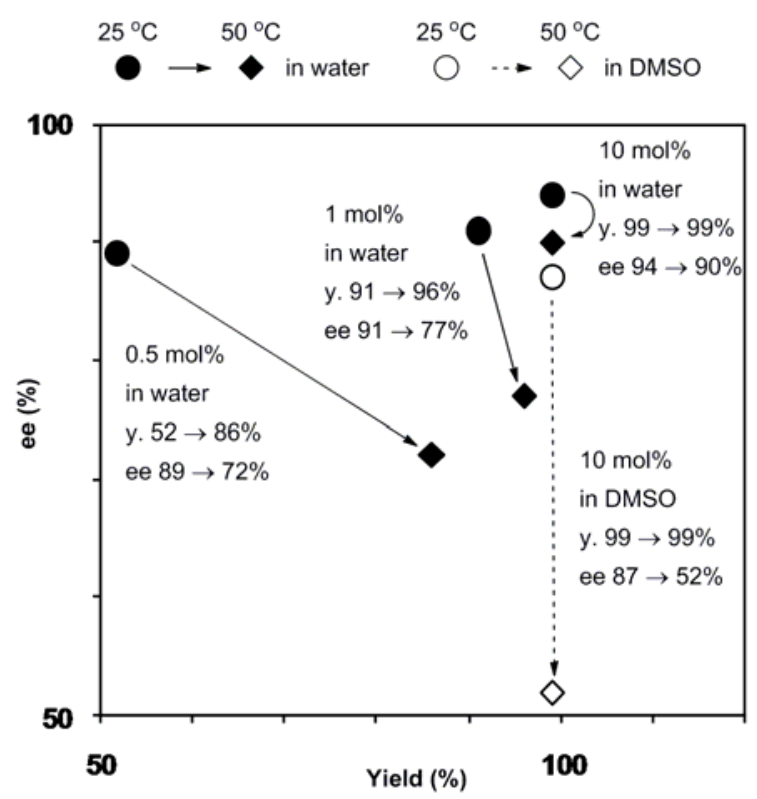

5 Figure 3. Temperature-dependent properties in the direct aldol reactions

Aldolase-type organocatalyst 5 forms an emulsion in water and organic substrate mixture. Although acceleration effect and excellent enantioselectivity in an aqueous enamine-based aldol reaction is very complex subject, we propose that 10 organocatalyst $\mathbf{5}$ with appropriate hydrophobic groups improves the chemical yield and stereoselectivity compared to reaction in organic solvent through the following mechanism (Figure 4, i). A liquid organic donor assembles in water due to hydrophobic interactions, which forms a metastable micelle 15 with the catalyst 5. Aggregation of the organic molecules excludes water from the organic phase and drives the equilibrium toward enamine formation. The enamine intermediate composed of the carbonyl donor and the catalyst $\mathbf{5}$ is more hydrophobic than that of the catalyst $\mathbf{5}$, therefore the 20 enamine intermediate moves into organic phase. It is believed that carbon-carbon bond formation between the enamine intermediate and the aldehyde acceptor occurs quickly in the highly concentrated organic micellular phase through a transition state similar to that observed in organic solvents and then hydrolysis of the enamine intermediate proceeds. ${ }^{13,15}$ 